\title{
Efeitos do contato entre categorias fonéticas distintas em contextos de imigração: uma revisão sobre o atrito de língua materna*
}

Felipe Flores Kupske

* Agradecemos à Coorden ação de Aperfeiçoamento de Pessoal de Nível Superior (CAPES) por financiar parte desta pesquisa (Processo BEX 6542/14-0).

\begin{abstract}
Resumo
Ainda são poucos os estudos, sobretudo no Brasil, que buscam investigar o processo de perda da lingua materna não patológica e não relacionada ao envelhecimento saudável, aqui tida como atrito linguístico, fenômeno frequente na produção e percepção dos sons da fala por imigrantes. Este trabalho de cunho qualitativo e bibliográfico, então, tem como objetivo apresentar um panorama sobre o atrito linguístico e sobre os efeitos do contato entre categorias fonéticas distintas na produção do Voice Onset Time por imigrantes em contexto de L2 dominante, buscando também discutir o caráter dinâmico da linguagem e popularizar essa área de investigação.
\end{abstract}

Palavras-Chave: Imigração. Atrito Linguístico. VOT. 


\section{Introdução}

Segundo Yilmaz e Schmid (2015), as populações de imigrantes estão em contínuo crescimento na sociedade contemporânea. Hoje, face às novas aberturas políticas, por exemplo, diversos países estão recebendo inúmeras comunidades de imigrantes de contextos socioculturais distintos, o que, como consequência, alimenta uma nova corrente de investigação na área da linguagem que tem a imigração em países de segunda língua ${ }^{1}$ (L2) dominante como foco de análise, como percebemos, por exemplo, por este volume temático acerca da imigração, práticas de linguagem e políticas linguísticas organizado pelas professoras Monica Savedra (UFF) e Konstanze Jungbluth (Universität Viadrina Frankfurt). Nesse cenário, a área da interfonologia tem se beneficiado desse novo e profícuo escopo de pesquisa, e é nela que focaremos.

Em alguns casos, após a imigração, o novo ambiente encoraja o uso de uma L2 em detrimento da língua materna (L1) utilizada no país de origem. Muitas das vezes, a L1 de um imigrante possui pouco ou nenhum espaço comunicacional no novo cenário e nesse sentido, gradualmente, começa a perder sua proeminência econômica, social e emocional, podendo "deteriorar", isto é, perder parte das características que tinha em um contexto monolíngue (YILMAZ; SCHMID, 2015). Essa perda é comum para bilíngues que, após longos períodos sem usar a L2, podem se deparar com algumas mudanças linguísticas, como, por exemplo, maior dificuldade e maior tempo no acesso lexical ou a aparente perda de fluência. Em outras palavras, como vulgarmente se diz em Português Brasileiro (doravante PB), a L2 torna-se "enferrujada". Logo, poucos falantes de uma L2, segundo Opitz (2011), irão negar esse processo de "deterioração" nas habilidades linguísticas de suas L2s, já que a manutenção dessas habilidades demanda um alto empenho quando o ambiente linguístico dominante

${ }^{1} \mathrm{O}$ presente trabalho não diferenciará os termos Segunda Língua e Língua Estrangeira, bem como Língua Materna e Primeira Língua. Assim, esses termos serão usados intercambiavelmente. não é favorável ou quando o aprendiz/ falante não procura por reforços linguísticos na L2 com regularidade (OPITZ, 2011). Nessa ótica, por analogia, um ponto que se considera nesse cenário acerca da "deterioração" linguística é o de que as habilidades em uma L1 também podem sofrer alterações quando não há um contexto favorável à sua produção ou falta 
reforço por parte do falante, como no caso da imigração para países com línguas distintas. É nessa temática, aqui tomada como atrito de L1, que este trabalho se debruçará.

A L2 dominante, em um contexto de imigração, parece não apenas influenciar o léxico, a morfologia, a sintaxe e fonologia/ fonética da L1, mas, para alguns imigrantes, pode até substituir suas L1s por tornar-se mais rápida e prontamente acessível pelo cérebro (SCHOOFS, 2013). Contudo, este trabalho tem como objetivo central apresentar um panorama sobre os efeitos específicos do contato entre categorias fonéticofonológicas distintas na produção do Voice Onset Time ${ }^{2}$ (VOT) por imigrantes em contexto de L2 dominante, buscando discutir o caráter dinâmico da linguagem e popularizar essa área drasticamente pouco pesquisada no Brasil. Para tanto, nesta pesquisa de cunho qualitativo e bibliográfico, iniciamos apresentando a interação entre categorias fonético-fonológicas, tomando como base os modelos de Flege $(1995,2007)$ e de Best e Tyler (2007). Damos continuidade, então, apresentando a temática do atrito linguístico, bem como os estudos na área que têm como objeto de análise o VOT. Finalizamos, então, com nossa discussão e considerações finais.

\section{A interação entre categorias fonéticas}

Historicamente, mesmo antes da sugestão de Lenneberg (1967) de que um Período Crítico pudesse existir para a aquisição de uma L2, diferenças entre o "padrão nativo" e o "não nativo" eram, usualmente, atribuídas ao processo, tido na época, como "interferência" linguística, isto é, à militância de estruturas previamente adquiridas sobre aquelas que se encontram em processo de aquisição. Nesse sentido, embora longe de conclusões categóricas, não há dúvida de que muito esforço já foi despendido no entendimento do processo de

${ }^{2} \mathrm{O}$ termo Voice Onset Time, grosso modo, faz referência ao tempo entre a soltura da oclusão e o início do vozeamento, sendo geralmente utilizado na produção e descrição d a s consoantes oclusivas. Maiores detalhes serão dados em seção específica. influência de uma L1 na aquisição de uma L2 (e.g. FLEGE, 1995; MACWHINNEY, 2002; BEST; TYLER, 2007).

Embora os mecanismos responsáveis pela relação entre percepção e produção na aquisição da linguagem não sejam explicitados, Flege $(1995,2002,2007)$ aponta que os mecanismos e processos aplicados à aquisição dos sons da L1, incluindo a formação de categorias, por exemplo, mantêm-se intactos durante toda a vida de um indivíduo, aplicando-se não apenas 
à aquisição de L2, mas, como apontam Evans e Iverson (2004), também à aquisição dialetal. Corroborando Flege (1995), Best e Tyler (2007) apontam que falantes continuam refinando, continuamente, suas percepções dos sons da fala, incluindo os de suas próprias L1s. Ainda segundo os autores, assim como já aponta Flege (1995), tanto as categorias da L1 quanto as da L2 coabitariam um mesmo espaço fonológico e, então, influenciam-se mutuamente. Nesse sentido, há um tempo razoável, já se sabe que o estado final de aquisição de um falante bilíngue não pode ser equiparado à soma de estados de dois monolíngues (e.g. GROSJEAN, 1998, 2001; COOK, 2006). Dessa forma, um falante bilíngue inerentemente se diferenciará de um monolíngue pela virtude de acessar um sistema de processamento linguístico integrado, o que, novamente, implica uma interação interlinguística entre ambas ou todas as línguas envolvidas em múltiplos níveis cognitivos e linguísticos, situação que falantes monolíngues não experienciam. Em consonância com esses estudos, pesquisas recentes acerca do componente fonético-fonológico (e.g. SANCIER; FOWLER, 1997; FLEGE, 2007; CHANG, 2010; SCHMID, 2010; KUPSKE, 2016) apontam que o processo de transferência é claramente bidirecional. Em outras palavras, a L2 também exerce força sobre o sistema de origem do processo aquisicional.

Os efeitos da interação entre L1 e L2 em bilíngues já são documentados acerca do processamento cognitivo (e.g. BIALYSTOK, 2009), do processamento linguístico em vários níveis simultaneamente (e.g. VAN HELL; DIJKSTRA, 2002), bem como sobre o léxico mental (e.g. HERNANDEZ; BATES; AVILA, 1994) e sobre o processamento de sentenças (e.g. CUTLER et al., 1989), entre outros. Dessa maneira, fica cada vez mais claro que o bilinguismo afeta os mecanismos e estratégias tanto do processamento da L2 quanto da própria L1 (DUSSIAS, 2004), assim como a velocidade do processamento em ambas as línguas (HOPP, 2010), mesmo que ambas as línguas sejam aprendidas desde a primeira infância (WERKER; BYERSHEINLEIN, 2008).

Assim, podemos pensar na língua como um sistema dinâmico, suscetível a modificações que são norteadas pelas novas experiências de um falante (BECKNER et al. 2009). A premissa de que falantes bilíngues podem apresentar uma performance em cada uma de suas línguas, que difere 
significativamente da dos monolíngues, tem sido corroborada por um crescente número de estudos, tanto no âmbito da percepção (e.g. BENKÍ, 2005; MAJOR, 2010; MAJOR, BAPTISTA, 2007), quanto no da produção dos sons (e.g. SANCIER, FOWLER, 1997; COHEN, 2004; FLEGE, 2007; LEE; IVERSON, 2011; KUPSKE, 2016). Essa sorte de estudos também tem se debruçado sobre diversos níveis linguísticos, tais como, por exemplo, do segmento vocálico (e.g. FLEGE, 1987; GUION, 2003; CHANG 2010), do segmento consonantal (e.g. FLEGE, 1987; FLEGE, EEFTING, 1987; FLEGE; HILLENBRAND, 1987; SANCIER; FOWLER, 1997; HARADA, 2003; COHEN, 2004; FLEGE, 2007; LORD, 2008; CHANG, 2010; SIMONS, 2011; LEE; IVERSON, 2011; KUPSKE, 2016), da sílaba (CARAMAZZA et al., 1973), e de aspectos suprassegmentais (e.g. COLANTONI; GURLEKIAN, 2004).

Nessa perspectiva de influência bidirecional, segundo Chang (2010, p. 64), os achados na área da percepção dos sons têm sugerido que é raro, senão impossível, que a performance de um falante bilíngue, em ao menos uma de suas línguas, não venha a diferir de seus falantes monolíngues de alguma forma. Ainda para o autor, as pesquisas apontam que a militância da L2 sobre a L1 virá à tona tanto em bilíngues precoces como em bilíngues adultos simultâneos ou sequenciais. Já é sabido, na literatura da área, que os sons da L1 tendem a flutuar em direção aos sons mais próximos da L2. Contudo, eles também podem flutuar em sentido oposto ao da L2, para que certos contrastes sejam mantidos no espaço fonético-fonológico (KUPSKE, 2016).

Flege (2007) aponta que há uma interação entre L1-L2. Ao resgatarmos duas das afirmativas propostas em seu Speech Learning Model (SLM - FLEGE, 1995), essa possibilidade nos é mais clara: (i) O SLM prega, primeiramente, que a aquisição de uma L2 não é restringida por um Período Crítico; e (ii) as capacidades necessárias para um monolíngue adquirir propriedades de sua L1 são preservadas por toda a vida e permanecem acessíveis a aprendizes de qualquer idade, embora, claro, sem desconsiderarmos os possíveis efeitos das diferentes idades de início de aquisição. Além disso, o SLM (FLEGE, 1995) aponta que as categorias que formam tanto a L1 quanto a L2 se encontram em um mesmo espaço fonológico (FLEGE, 2007) e podem, então, influenciar uma à outra, como 
já sinalizado. Ainda para Flege (2007), o SLM propõe dois mecanismos pelos quais as categorias da L1 e L2 podem interagir: (i) assimilação de categoria fonética; e (ii) dissimilação de categoria fonética.

Os sistemas de L1 e L2 irão interagir via assimilação da categoria fonética quando a formação de uma nova categoria da L2 é bloqueada por um processo de classificação dessa categoria como equivalente a uma categoria já existente da L1. Assim sendo, um aprendiz de L2 irá, a princípio, usar o som mais próximo da L1 ao produzir o som da L2. Contudo, e ainda para Flege (2007), o SLM prevê que, quando a formação de uma categoria é bloqueada, a produção de um som da L2 será modificada lentamente através do tempo se o som da L2 diferir acusticamente do som mais próximo da L1 utilizado como equivalente. Essa evolução, contudo, será limitada, já que a representação linguística na memória de longo prazo será utilizada para processar tanto o som da L1 quanto da L2. Essa categoria fonética, então, irá modificar-se ao longo do tempo, mas, como é utilizada para balizar a produção em ambas as línguas, haverá mudanças na produção também em ambas as línguas, como aponta o Merger Hypothesis (FLEGE, 2007). É valido ressaltar que, de acordo com o input recebido, essa "categoria fundida" poderá ser mais próxima da representação dos monolíngues da L1 ou da L2. Quanto mais experiência na língua $X$, mais robusta essa categoria híbrida será em direção às produções de $X$ (KUPSKE, 2016). Nesses casos, quando a produção de um segmento da L1 aproxima-se do esperado para a L2, temos, então, um caso de atrito de L1, isto é, uma L1 que agora apresenta características acústicas da L2.

Por outro lado, quando um imigrante estabelece uma categoria nova para um som da L2, seu espaço fonológico, onde ambas as línguas se alojam, segundo o SLM (1995), torna-se mais lotado. Contudo, ainda para o SLM, as categorias da L1 e da L2 tendem a dispersar para que o contraste fonético seja mantido. Para Flege (2007), essas novas categorias podem dissimilar de um som da L1 próximo (ou vice-versa) quando implementações das categorias da L1 e L2 forem confusas. Nesse caso, a produção de um som da L1 ou da L2 de um imigrante bilíngue deverá ser diferente da produção de monolíngues. Assim, existe a interação entre categorias de L1 e L2 face à dissimilação de categoria fonética. Novamente, quando se tem 
um som da L1 sendo produzido de forma diferenciada, há um caso de atrito, como será abordado a seguir.

\section{Atrito Linguístico}

A temática "atrito linguístico" parece exercer um estranho fascínio. A questão sobre um indivíduo poder perder sua L1 ou L2 após aprendida, e como e por que essa "perda" pode acontecer, é uma questão ainda bastante intrigante. Segundo Köpke e Schmid (2004), a maioria das pessoas que aprenderam uma língua estrangeira na educação básica, por exemplo, irá considerar-se "atritada (falantes atritados)", isto é, falantes que apresentam uma defasagem, de alguma forma, em um sistema que outrora não existia, como já sinalizado em nossa introdução. Muito embora esse fascínio seja tão antigo quanto a própria ciência da linguagem, é apenas nas últimas décadas que vem sendo construído um saber científico sobre essa temática; ainda muito limitado, contudo (KUPSKE, 2016).

Segundo Schmid (2010), a metáfora por trás do nome "atrito" não é uma das mais felizes, parcialmente pelo fato de a existência de muitas colocações negativas do termo e pela suposição de que o atrito evoca, categoricamente, um certo processo de redução face a um possível e constante lixamento de substâncias ou tecidos, por exemplo. Entretanto, assim como a maioria dos estudos que se debruçam nessa temática, adotamos essa nomenclatura, pois, segundo Kupske (2016), "atrito" simboliza a força resultante do contato de dois corpos, no caso, duas línguas, que se tocam, mas não se estabilizam, havendo uma constante tendência ao movimento.

Para Kupske (2016), o atrito de L1, assim como tomado no presente trabalho, estabelece-se na comunidade científica apenas na última década. Por algum tempo antes dessa revolução na área, que tem seu início marcado em 1982, o campo da perda da linguagem estava interessado em fatores instrumentais sobre a mudança linguística e a morte linguística em comunidades de contato linguístico, como, por exemplo, imigrantes de segunda e terceira geração, bem como minorias sociais. $\mathrm{O}$ interesse desses estudos focava o nível de grupo/comunidade de falantes, bem como os fatores socioeconômicos que militavam nessas mudanças. Contudo, com o estabelecimento da pesquisa em atrito, o processo 
psicolinguístico na perda individual da linguagem recebe um novo foco, o uso e a proficiência individual, englobando, também, o impacto, então, de fatores pessoais, mesmo que estes estejam ligados a fatores sociais (OPITZ, 2011).

Em linhas gerais, atrito pode ser definido como "declínio de qualquer língua (L1, L2, ou língua outra), habilidade ou parte dela em um falante saudável" (ECKE, 2004, p. 322). Delimitandonos na L1, para Schmid (2007), o atrito pode ser definido de duas formas, como um processo ou como um fenômeno. A definição de atrito como processo é, de certa forma, simples: de maneira geral, pode ser definido como a perda não patológica do falar nativo de um individuo (KÖPKE; SCHMID, 2004). Em outras palavras, investiga a situação na qual um falante já não consegue fazer algo que anteriormente conseguia, sendo que essa perda não é oriunda de uma deterioração cerebral, doença ou idade. Assim, para Goral (2004), mais especificamente, o atrito refere-se a perdas não relacionadas à idade, sendo que vários estudos evidenciam que algumas habilidades linguísticas podem mudar com o avançar da idade. Segundo Goral (2004), esse tipo de perda de linguagem, que ocorre no envelhecimento saudável, já foi também descrito como atrito, embora, hoje, o foco dos estudos em atrito seja o contexto de bilinguismo. Então, atrito, comumente, relata a perda de uma língua por uma mudança no comportamento linguístico de um falante face a um contato escasso com a comunidade em que a língua que sofre o processo é falada (SCHMID, 2007). Há dois cenários prováveis principais para esse caso: 1) quando todo o contato com aquela língua foi interrompido, não havendo mais input linguístico ou comunicação orgânica; ou 2) quando há uma grande competição com outros sistemas linguísticos, como no caso de imigrantes.

O atrito enquanto fenômeno é um pouco mais difícil para ser definido. Primeiramente, ao entendermos o atrito como processo, devemos prever dois estágios de um falante atritado, o estágio pré-atrito (A) e o estágio de atrito (B), sendo que esse ínterim entre A e B faria referência ao fenômeno atrito. No momento em que podemos, de fato, dizer que o Momento B é diferente do Momento A, podemos dizer que o fenômeno de atrito em L1 se estabeleceu.

Já para Major (2010), o atrito de L1 pode ser definido como qualquer mudança na produção e/ou percepção que não 
caracteriza falantes típicos de uma mesma língua ou dialeto ou que não ocorre com esses falantes. Para Schmid (2010), o termo 'atrito' se aplica quando um bilíngue alcança um elevado nível de proficiência de uma L2 por utilizá-la com grande frequência e regularidade e, como consequência, apresenta uma maior variabilidade na forma, como propriedades lexicais, gramaticais ou fonéticas são aplicadas na L1. Segundo Cook (2006), esse fenômeno pode acontecer em diversos níveis, desde pequenas modificações, por exemplo, em nível de produção fonética, até a perda temporária ou permanente da L1 - morte linguística. Esse processo é bastante evidenciado em falantes que migraram para países nos quais uma L2 é dominante (KÖPKE, SCHMID, 2004).

Ainda nesse contexto terminológico, alguns autores irão diferenciar perda estrutural da perda funcional. Köpke (2004), nesse sentido, define atrito como a perda de aspectos estruturais de uma língua, como, por exemplo, mudanças de forma. Ainda para a autora, a mudança de aspectos funcionais estaria vinculada à mudança linguística (Language Shift), como, por exemplo, nos casos em que há uma substituição gradual de uma língua por outra com respeito ao uso, isto é, mudança ou alteração no papel/ função que uma L1 detém na vida de um indivíduo.

Neste trabalho, então, adota-se o atrito linguístico de L1 como a perda estrutural não patológica e não relacionada ao envelhecimento saudável da língua materna de um indivíduo. Aqui, também é importante ressaltar a diferença entre perda da língua em um indivíduo e a perda social de uma língua (DE BOT, 2001), sendo que a perda social de uma língua acontece quando poucos ou nenhum falante resta de uma língua particular em uma população que um dia a falou. Para Crystal (2005), em casos extremos, uma língua morre quando ninguém mais a fala.

\section{Voice Onset Time}

O termo Voice Onset Time, grosso modo, faz referência ao tempo entre a soltura da oclusão e o início do vozeamento, sendo geralmente utilizado na produção e descrição das consoantes oclusivas. Para Lisker e Abramson (1964), é senso comum em fonética dizer que as categorias das oclusivas em 
várias línguas podem ser divididas em grupos que diferem sobre o vozeamento: oclusivas sonoras apresentam vibração glotal durante o intervalo da oclusão, enquanto a não presença dessa vibração é a marca das oclusivas surdas. Ainda para os autores, espectrograficamente, os dois tipos de oclusivas são, na maioria dos casos, facilmente distinguidos. Em termos acústicos, os segmentos sonoros apresentam a presença de energia de baixa frequência na região de seu primeiro formante. Por outro lado, as surdas apresentam um período de silêncio completo, dada a abertura da glote, o que permite a passagem ininterrupta do ar fonatório (LISKER; ABRAMSON, 1964).

O VOT, então, pode ser dividido em três categorias, segundo Lisker e Abramson (1964), sendo elas: a) VOT negativo (também conhecido como pre-voicing), em que há vozeamento antes da barra de explosão de valor entre $-125 \mathrm{~ms}$ e $-75 \mathrm{~ms}$, compreendendo as oclusivas vozeadas; b) VOT zero, que apresenta um período de surdez pequeno ou nulo, em que o início de vozeamento e a soltura ocorrem em um período bastante próximo, em torno de 0 a $10 \mathrm{~ms}$, compreendendo as oclusivas surdas sem aspiração; e c) VOT positivo, que possui um intervalo longo entre a barra de explosão e o início do vozeamento, em torno de $+75 \mathrm{~ms}$, que compreende as oclusivas surdas aspiradas.

Este trabalho, então, focará na análise dos efeitos do contato entre duas categorias fonéticas distintas para o VOT no contexto de imigração. Isto é, são dados coletados por outras pesquisas de imigrantes que, em suas L1s, possuem uma categoria de VOT sem aspiração/ short lag, mas que residem em países com L2 dominante que possui uma categoria de VOT com aspiração/ long lag, ou o exato oposto. Em outras palavras, dados que revelam o atrito linguístico oriundo do contato com VOTs mais longos ou mais curtos do que os presentes na L1.

\section{Atrito e a produção do VOT: um panorama}

Assim como mencionado por Flege (2007), segundo Eckman e Iverson (2012), trabalhos atuais sobre a aquisição de L2 revelam como o contato com a L2 pode acarretar mudanças fonéticas no sistema de L1 de um imigrante. Para Flege e Hillenbrand (1984), de maneira generalista, no bilinguismo, os valores de VOT da L2 tendem a ir em direção 
aos valores de VOT da L1. Por outro lado, ao mesmo tempo, valores para o VOT na L1 de falantes bilíngues tendem à aproximação dos valores da L2. Um dos estudos pioneiros nessa área de investigação é o de Caramazza et al. (1973), que analisa a produção e percepção das plosivas surdas em canadenses monolíngues e bilíngues (inglês - francês), tendo como resultado valores de produção de VOT em L1 para os bilíngues que eram intermediários entre os valores esperados para os monolíngues de ambas as línguas. Essa pesquisa torna-se, então, um marco nos estudos da área do atrito fonético-fonológico, pois é uma das primeiras a verificar que, em falantes que aprenderam mais de uma língua, a interação entre esses sistemas é mútua, isto é, não é unidirecional.

No que concerne, especificamente, ao atrito em L1 e ao VOT, estudos como, por exemplo, os de Flege e Eefting (1987), Flege (1987), Sancier e Fowler (1997), Major (1992), Cohen (2004), Toribio et al. (2005), Flege (2007), Lord (2008) e Chang (2010) apontam, assim como em Caramazza et al. (1973), que bilíngues irão apresentar valores intermediários (ou próximos disso) de VOT para a L1 quando línguas de diferentes categorias/ padrões de VOT (long lag x short lag) estão envolvidas no processo. Assim, apontam que esses valores são diferentes das médias esperadas para os monolíngues dessas línguas. Resenharemos, agora, estudos que têm como objeto a produção de VOT por imigrantes adultos.

Nas últimas décadas, logo, baseando-se nos estudos de Caramazza et al. (1973) e em um movimento advogado por Flege (1987) e seus colegas (e.g. FLEGE; EEFTING, 1987), os estudos acerca da mudança em L1 acarretados pela experiência com a aquisição e uso de um sistema de L2 começam a tomar mais força no domínio da aquisição da linguagem. Um dos trabalhos mais importantes nessa perspectiva, focando nos estudos de oralidade, é o de Ventureyra, Pallier e Yoo (2004). Nessa investigação, os autores estudaram 18 informantes coreanos adultos que foram adotados e criados por famílias de falantes nativos do francês na França, Suíça e na Bélgica. Os resultados apontaram que, na identificação dos contrastes do coreano, os informantes obtiveram os mesmos índices dos monolíngues falantes do francês. Em outras palavras, após a imigração, apresentam uma performance em sua L1 coerente com a de um falante estrangeiro. 
Flege e Eefting (1987) examinaram a produção das oclusivas sonoras e surdas em posição inicial em inglês (long lag) e espanhol (short lag) por dois grupos de falantes espanhóis adultos e um grupo de falantes entre nove e dez anos, que começaram a aprender o inglês (L2) entre os 5 e 6 anos de idade. Nesse trabalho, então, os autores confirmam sua hipótese de que o grupo de adultos e o grupo de crianças produziram as oclusivas surdas do inglês com valores menores quando comparados aos valores esperados para um falante nativo do inglês. Embora os grupos de falantes nativos do espanhol tenham produzido $/ \mathrm{p}, \mathrm{t}, \mathrm{k} / \mathrm{com}$ valores significativamente mais longos em inglês do que em sua L1, tais participantes realizaram esse grupo de segmentos com valores mais curtos de VOT quando comparados com os falantes nativos da língua alvo. Os autores apontam, também, que os valores de VOT eram quase perfeitamente intermediários $(57 \mathrm{~ms})$ para as médias observadas para os monolíngues do espanhol (26 $\mathrm{ms}$ ) e para os monolíngues do inglês (87 ms). Ainda para os autores, dessa forma, novamente, a L1 de um falante bilíngue pode apresentar valores distintos dos valores esperados para o falante monolíngue de uma mesma língua. Contudo, em suas produções de L2, também não apresentam os valores esperados para um monolíngue dessa L2, como se o sistema desses falantes estivesse, de certa forma, adaptado a ambos os contextos.

Flege (1987) também revela evidências de que o espaço fonético-fonológico das categorias da L1 pode mudar quando os aprendizes estão imersos em um ambiente em que a L2 é dominante por longos períodos de tempo. No estudo em questão, o autor examinou a produção de falantes nativos do inglês americano (IA - long lag) imigrantes em Paris e nativos do francês (short lag) imigrantes em Chicago. Quanto às produções de $[\mathrm{t}]$ e [ $\left.\mathrm{t}^{\mathrm{h}}\right]$ em posição inicial, o estudo aponta que a oclusiva aspirada em língua inglesa foi produzida pelos nativos do IA de Paris com um valor de VOT de $56 \mathrm{~ms}$, sendo que o valor esperado, segundo o autor (1987, p. 423), é de 77 ms. Por outro lado, os franceses de Chicago apresentaram, para produções em francês, um valor de $51 \mathrm{~ms}$ para a oclusiva não aspirada, sendo que o valor estimado para o monolíngue é de $33 \mathrm{~ms}$. Ainda nessa linha de pensamento, Toribio et al. (2005) também investigaram a produção do VOT por falantes 
bilíngues imigrantes do inglês e do espanhol, apontando, novamente, que a produção desses falantes não se daria nos termos dos padrões para os monolíngues de ambas as línguas. Novamente, apresentam valores de entremeio.

Sancier e Fowler (1997) propõem três instrumentos de coleta para a investigação do que denominam Gestural Drift (deriva ou flutuação gestual) - mudanças na produção acarretadas por alterações perceptuais - para uma imigrante brasileira residente nos EUA que, uma vez ao chegar ao Brasil, escutou de seu pai que sua fala andava "muito explosiva" (SANCIER; FOWLER, 1997, p. 421). Embora discordando das autoras quanto ao fato de que, para elas, não haveria motivação social para uma afiliação social (tentativa de pertencer a uma comunidade de fala) no caso de sua informante brasileira nos EUA (SANCIER; FOWLER, 1997, p. 422), concordamos que uma das fontes para a deriva gestual pode ser pela disposição de um falante/ouvinte imitar o que escuta, imitação fomentada pela percepção. A hipótese, que foi confirmada, que sustentava o primeiro experimento, era de que falantes nativos do PB iriam perceber a fala da informante como contendo sotaque após exposição massiva ao inglês nos EUA. A segunda hipótese, não confirmada, para o segundo experimento, era de que falantes nativos do inglês iriam perceber um aumento de sotaque na fala da informante no seu retorno aos EUA, após alguns meses no Brasil. $\mathrm{O}$ terceiro experimento tentava elucidar a hipótese de que a informante teria seus valores de VOT aumentados quando nos EUA e, por outro lado, diminuídos quando no Brasil. Essa hipótese apenas foi significativa para $\left[\mathrm{p}^{\mathrm{h}}\right]$ do inglês americano (IA) e [p] do PB. Assim, essa pesquisa aponta que a imigrante modificava os valores na produção do VOT, dependendo do contexto linguístico em que se encontrava. No mesmo prisma, Major (1992) aponta que falantes nativos do inglês imigrantes no Brasil por períodos maiores do que doze anos, grosso modo, modificaram seus valores de VOT tanto para sua L1 (inglês) quanto para o PB (L2).

Simons (2011) analisa a aquisição bilíngue de contrastes laríngeos e em até que ponto estes podem nos revelar a origem dos sistemas laríngeos de línguas germânicas como o holandês, com contraste entre oclusivas pré-vozeadas e não aspiradas. A autora aponta, como resultado, que tanto a imposição quanto o empréstimo podem ocorrer quando línguas aspiradas entram 
em contato com línguas sem aspiração, ao analisar o cenário de falantes das línguas germânicas em contato com um cenário falante de línguas românicas.

Kupske (2016) explorou a produção de plosivas surdas em posição inicial de palavra de vinte e dois participantes, com idades entre 18-40 anos, por parte de imigrantes brasileiros que viviam em Londres por períodos de tempo variados, bem como por monolíngues do português brasileiro. A produção dos participantes do grupo-experimental com o menor período de tempo de residência (LOR) em Londres não era estatisticamente diferente da dos monolíngues do PB. Por outro lado, imigrantes com um LOR entre quatro e sete anos produziram valores de VOT estatisticamente diferentes dos produzidos pelos controles do PB para [t] e [k], apresentando valores médios mais elevados. Os residentes na Grã-Bretanha entre oito e onze anos revelaram diferenças em relação aos controles do $\mathrm{PB}$, apresentando os maiores valores de VOT para todos os sons plosivos considerados. Esses dados também confirmam que o sistema de L1 não é rígido e que pode apresentar alterações durante o tempo de vida de um falante. Esses resultados, assim, dão suporte à descrição da linguagem como um sistema dinâmico e aberto a novos estímulos e padrões.

Como podemos perceber, vários estudos já tentam demonstrar que a imigração para países nos quais a L1 não é dominante afeta a produção e a percepção dessa, acarretando o atrito linguístico (MAJOR; BAPTISTA, 2007). Em outras palavras, o processo de imigração pode levar a uma perda - ao menos no nível fonético de produção do VOT - da L1.

\section{Discutindo o atrito na imigração em países de L2-dominante}

O discutido neste trabalho sinaliza que o processo de transferência também se aplica e influencia o sistema de L1 de um falante bilíngue, evidente na produção de imigrantes. Tanto para Flege (1995) quanto para Best e Tyler (2007), a capacidade humana para a aquisição da oralidade não é restringida por um período crítico. Muito embora os autores deixem claro que a idade possui um papel efetivo no processo, os mecanismos para a aquisição de uma L1 permanecem intactos pela vida de um indivíduo. Além disso, tanto Flege (1995) quanto Best e 
Tyler (2007) sinalizam que as línguas envolvidas no processo de aquisição coabitam um mesmo espaço fonético-fonológico. Assim, além de um indivíduo manter suas habilidades de aprendizagem de línguas, elas, as línguas, poderiam interagir entre si de forma bidirecional, já que não são mais pensadas como sistemas categoricamente separados. Nesse sentido, concordamos com Schmid (2013) na afirmação de que bilíngues que recebem mais input extensivo, ou o recebem por mais tempo, tendem a apresentar uma transferência mais intensiva e mais perceptiva.

Uma das grandes evidências desse processo bidirecional é, exatamente, o atrito de L1, como nos dados acima brevemente resenhados. Assim sendo, o estudo de atrito linguístico serve como uma evidência de que a aquisição da linguagem apresenta uma complexidade muitas vezes ignorada, como os efeitos do contato com uma L2-dominante para a L1 de imigrantes. Podemos levantar a hipótese, assim como sinaliza Kupske (2016), de que o comportamento de um imigrante é a consequência de fatores em competição, variando de restrições perceptuais até motivações de cunho social e de que as estruturas das línguas emergem dos padrões inter-relacionados de empiria, interação social e mecanismos/processos cognitivos. Percebemos, então, e como mostram os dados dos estudos apresentados nesta revisão, que os processos de categorização linguísticas são constantes, sendo que, seguindo-se Flege (1995) e Best e Tyler (2007), até mesmo gramáticas adultas não são rígidas, possuindo potencial e plasticidade para se alterar face a novos insumos/ experiências/ambiente.

Na imigração, há, assim, contexto favorável para a transferência linguística, tida como a interação dos sistemas de L1 e L2 (ALVES et al., 2011). Assim, fica evidente que o bilinguismo, seguindo-se Dussias (2004) e Hopp (2010), perturba os mecanismos e estratégias tanto do processamento da L2 quanto da própria L1. Chang (2010) sinaliza que é raro, senão impossível, que a performance de um bilíngue, em ao menos uma de suas línguas, não venha a diferir de seus falantes monolíngues de alguma forma, sobretudo para o caso dos imigrantes em um contexto de L2-dominante. 


\section{Considerações finais}

Major e Baptista (2007) e Schmid (2010) sinalizam que alguns poucos trabalhos, comparados ao corpo teórico acerca do desenvolvimento de L2, já tentam demonstrar que a residência em países nos quais a L1 de um falante não é dominante pode afetar a performance de produção e de percepção nessa L1 (e.g. CARAMAZZA et al., 1973; FLEGE, 1987; FLEGE; EEFTING, 1987; SANCIER; FOWLER, 1997; ROCCA, 2003; TORIBIO et al., 2005; LEE; IVERSON, 2011). Neste trabalho, então, buscamos apresentar os trabalhos que consideramos seminais acerca do atrito de língua materna com foco no VOT, para popularizarmos essa temática vinculada à imigração que ainda se encontra à margem dos estudos linguísticos brasileiros.

No decorrer do trabalho, pudemos perceber que tanto a L1 quanto a L2, ao menos em alguns níveis, interagem mutuamente, independentemente da proficiência do imigrante em uma comunidade de L2-dominante, justificando, assim, um possível processo de deterioração linguística, como visto. Ainda nesse sentido, para Pavlenko e Jarvis (2002), por exemplo, as línguas envolvidas no processo de aquisição interagiriam não apenas entre si, mas também com outros fatores externos/ ambientais de maneira contínua. Contudo, devemos concordar com Schmid (2013) de que a pesquisa em atrito ainda é muito inicial e não está apta a identificar todos os fatores que prevejam esse fenômeno. Mantém-se, então, esta questão em aberto: a tentativa de explicar o que faz alguns imigrantes atritarem, e outros, por exemplo, manterem níveis nativos da L1. Muito ainda há para ser feito.

Podemos perceber, todavia, que a perda não patológica da linguagem não pode ser acomodada, na forma como é entendida, hoje, em qualquer modelo teórico. Longe de conclusões categóricas, esse compêndio de pesquisas sobre o atrito corrobora De Bot e Makoni (2004) de que a língua é um sistema dinâmico, composto por variáveis que interagem e que está em permanente mudança, já que é influenciada pelo ambiente e pelo próprio processo de autoestruturação, já que a própria L1 de um falante, por muito tempo vista como estática, pode variar ao longo de sua vida a ponto de não ser reconhecida como tal. A essa luz, concordamos 
com Zimmer e Alves (2014) quando dizem que o paradigma complexo/dinâmico representa um norte para entendermos a complexidade inerente à linguagem, como no caso do atrito de L1. Ensejamos, então, que esta pesquisa tenha trazido à tona mais perguntas do que respostas e que fomente essa área de estudo ainda pouco pesquisada. Fica, então, nosso apelo e sugestão para futuras investidas.

\section{REFERÊNCIAS}

ALVES, U.; SCHWARTZHAUPT, B.; BARATZ, A. A percepção dos padrões de VOT longo do inglês por aprendizes brasileiros. III SAF -Seminário de Aquisição Fonológica, 2011 - Programação e Resumos. Pelotas-RS : Editora da UFPel, 2011. p. 88-89.

BECKNER, C.; BLYTHE, R.; BYBEE, J.; CHRISTIANSEN, M.; CROFT, W.; ELLIS, N.; HOLLAND, J.; KE, J.; LARSENFREEMAN, D.; SCHOENEMANN, T. Language is a complex adaptive system: position paper. Language Learning, v.59, n.1., p.1-26, Dec., 2009.

BENKÍ, J. Perception of VOT and first formant onset by Spanish and English speakers. In: COHEN, J.; McALISTER, K.; ROSLAND, k.; MacSWAN (eds.) Proceedings of the 4th International Symposium on Bilingualism. Somerville/MA: Cascadilla Press, 2005. p.240-248

BEST, C.; TYLER, M. Nonnative and second-language speech perception: Commonalities and complementarities. In: BOHN, Ocke-Schwen; MUNRO, Murray J. (eds). Language experience in second language speech learning: In honor of James Emil Flege. Amsterdam: John Benjamins, 2007. p.13-34.

BIALYSTOK, E. Metalinguistic aspects of bilingual processing. Annual review of applied linguistics, v.21, n.1, p. 169-181, 2009.

CARAMAZZA, A.; YENI-KOMSHIAN, E., ZURIF, E.; CARBONE, E., The acquisition of a new phonological contrast: the case of stop consonants in French-English bilinguals. Journal of the Acoustical Society of America, v.54, n.2, p. 421-428, 1973.

$\mathrm{CHANG}, \mathrm{C}$. B. First language phonetic drift during second language acquisition. Ph.D. Thesis, Berkeley, CA: University of California, Berkeley, 2010. 
COHEN, G. The VOT dimension: a bi-directional experiment with English and Brazilian-Portuguese stops. 2004. 70f. Dissertação (Mestrado em Letras). Universidade Federal de Santa Catarina. 2004.

COLANTONI, L.; GURLEKIAN, J. Convergence and intonation: Historical evidence from Buenos Aires, Spanish. Bilingualism: Language and Cognition, v.7, n.2, p. 107-119, 2004.

COOK, V. Introduction: The Changing L1 in the L2 User's Mind. Effects of the Second Language on the First. Clevedon/Buffalo/ Toronto/Sydney: Multilingual Matters, 2006. p.1-18.

CRYSTAL, D. Towards a philosophy of language diversity. Paper given to conference on 'Dialogue of Cultures', Reykjavik, 14 April, 2005.

CUTLER Cutler,A.,j. Hawkins, and G. Gijligan. 1985. The suffixing preference: A processing explanation'. Linguistics, v.23, n.72, p.3-58, 1989.

De BOT, K. Languages in contact: trilingualism and remembering. In: SCHRÖDER, H.; KUMSCHLIES, P.; GONZALES, M. (eds.). Linguistik als Kulturwissenschaft. Festschrift für Bernd Spillner zum 60. Geburtstag. Frankfurt a/M: Peter Lang, 2001. p. 223-229.

DUSSIAS, P. E. Parsing a first language like a second: The erosion of L1 parsing strategies in Spanish-English bilinguals. International Journal of Bilingualism, v.8, n.3, p. 355-371, 2004.

ECKE, P. Language attrition and theories of forgetting: A cross-disciplinary review. International Journal of Bilingualism, v.8, n.3, p. 321-354, 2004.

ECKMAN, F.; IVERSON, G. The role of native language phonology in the production of L2 contrasts. Studies in Second Language Acquisition, 2012.

FLEGE, J. Second language speech learning: Theory, findings, and problems. In: STRANGE, Winifred (ed.). Speech perception and linguistic experience: Issues in cross-language research. Timonium, MD: York Press, 1995. p. 233-277.

FLEGE, J. Assessing constraints on second-language segmental production and perception. In: MEYER, A.; SCHILLER, N. (Eds). Phonetics and Phonology in Language Comprehension and Production, Differences and Similarities. Berlin: Mouton de Gruyter, 2003. p. 319-355. 
FLEGE, J. Interactions between the native and second-language phonetic systems. In BURMEISTER, P.; PISKE, T; ROHDE, A. (eds.), An integrated view of language development: Papers in honor of Henning Wode (pp. 217-244). Trier, Germany: Wissenschaftlicher Verlag, 2002.

FLEGE, J. Language contact in bilingualism: Phonetic system interactions. In: COLE, J.; HUALDE. J. (eds.), Laboratory phonology, 9. Berlin, Ger.: Walter de Gruyter, 2007. p. 353-382.

FLEGE, J.; EEFTING, W. Cross-language switching in stop consonant perception and production by Dutch speakers of English. Speech Communication, v.6, n.3, p. 185-202, 1987.

FLEGE, J.; HILLENBRAND, J. Limits on phonetic accuracy in foreign language production. Journal of the Acoustical Society of America, n.76, p.708-721, 1987.

GORAL, M. First language decline in healthy aging: Implications for attrition in bilingualism. Journal of Neurolinguistics, v.17, n.1, p. 31-52, 2004.

GUION, S. G. The vowel systems of Quichua-Spanish bilinguals: Age of acquisition effects on the mutual influence of the first and second languages. Phonetica, v.60, n.2, p. 98-128, 2003.

HARADA, T. L2 influence on L1 speech in the production of VOT. In ROMERO, J. (Eds.). Proceedings of the 15th International Congress of Phonetic Sciences, Barcelona, Spain: Causal Productions, 2003. p. 1085-1088.

HEINE, B.;KUTEVA, T. Onconctact-induced grammaticalization. Studies in language, v. 27, p. 529-572, 2007.

HERNANDEZ, A., BATES, E., AVILA, L. On-line sentence interpretation in Spanish-English bilinguals: What does it mean to be "in between"? Applied Psycholinguistics, v.15, p.417446, 1994.

$\mathrm{HOPP}, \mathrm{H}$. Ultimate attainment at the interfaces in second language acquisition: Grammar and processing. (Unpublished Doctoral dissertation). University of Groningen, 2010.

KOPKE, B. Neurolinguistic Aspects of Attrition. Journal of Neurolinguistics, v.17, n.1, p.3-30, 2004.

KOPKE, B.; SCHMID, M. Language Attrition: The Next Phase. In: SCHMID, M.; B. KÖPKE, B.; KEIJZER, M.; WEILEMAR, L. (eds). Language Attrition: Interdisciplinary Perspectives on Methodological Issues. Amsterdam: John Benjamins, 2004. p.1-43. 
KUPSKE, F. Imigração, Atrito e Complexidade: a produção das oclusivas surdas iniciais do inglês e do português por brasileiros residentes em Londres. 2016. 233f. Tese (Doutorado em Letras). Instituto de Letras, Universidade Federal do Rio Grande do Sul, 2016.

KUPSKE, F.; ALVES, U. A fala de imigrantes brasileiros de primeira geração em Londres como evidência empírica para a língua como um Sistema Adaptativo Complexo. ReVEL, v.14, n. 27, 2016. Disponível em: < http://www.revel.inf.br/files/ e166bf461eec067bb8459c6617d5fd52.pdf >. Acesso em: 14 jan. 2017. LEE, S.; IVERSON, G.. Stop consonant of English-Korean bilingual children. Bilingualism: Language and Cognition, v.15, n.2, abr. 2012, publicado online 11 jul. 2011.

LENNEBERG, E. Biological Foundations of Language, New York: Wiley, 1967.

LISKER, L.; ABRAMSON, A. A cross-language study of voicing in initial stops: Acoustical measurements. Word, v. 20, n. 3, p. 384-422, 1964.

LORD, G. Second language acquisition and first language phonological modification. In: GARAVITO, J.; VALENZUELA, E. (Eds.), Selected proceedings of the 10th hispanic linguistics symposium. Somerville, MA: Cascadilla Proceedings Project, 2008. p. 184-193.

MACWHINNEY, B. Language Emergence. In: BURMEISTER, P.; PISKE T.; RHODE, A. (Ed.) An integrated view of language development. Papers in honor of Henning Wode. Trier: Wissenchaftliche Verlag, 2002. p.17-42.

MAJOR, R. C. First language attrition in foreign accent perception. Journal of Bilingualism, v.14, n.2, p. 163-183, 2010.

MAJOR, R. C.; BAPTISTA, B. First language attrition in foreign accent detection. In: WATKINGS, M., RAUBER, A., BAPTISTA, B. (Org.). Recent research in second language phonetics/phonology: Perception and production. 1ed. Newcastle Upon Tyne: Cambridge Scholars, 2007.

OPITZ, C. First language Attrition and Second Language Acquisition in a Second-Language Environment. PhD dissertation, Trinity College Dublin, 2011. 
SANCIER. M. L.; FOWLER, C. A. Gestural drift in a bilingual speaker of Brazilian Portuguese and English. Journal of Phonetics, 27(4), p. 421-436, 1997.

SCHMID, M. S. The Role of L1 Use for L1 Attrition. In: KÖPKE, B.; SCHMID, M. S.; KEIJZER; M.; DOSTERT, S. (eds), Language Attrition. Theoretical perspectives. Amsterdam/Philadelphia: John Benjamins, 2007. p. 135-153.

SCHMID M.S. Language Attrition. Cambridge University Press, 2011. (Key Topics in Sociolinguistics series)

SCHMID, M. S. First Language Attrition. WIREs Cognitive Science v.4, n.2, p. 117-123, 2013.

SCHOOFS, P. The mutual influence of the first and second languages in German and English L1 speakers in second language environments . PhD dissertation, University of Newcastle Upon Tyne, 2013. SIMONS, E. Laryngeal Stop Systems in Contact: Connecting Present-Day Acquisition Findings and Historical Contact Hypotheses. Diachronica v.28, n.2. p. 225-54, 2001.

TORIBIO, A; BULLOCK, B.; BOTERO, C.; DAVIES, K. Perseverative phonetic effects in bilingual code-switching. In GESS, R. S.; RUBIN, E. J. (eds.), Theoretical and experimental approaches to Romance linguistics. Salt Lake City: John Benjamins, 2005. p. 291-306

VAN HELL, J.G.; DIJKSTRA, T., Foreign language knowledge can influence native language performance in exclusively native contexts. Psyconomic Bulletin and Review, n.9, 780-789, 2002.

VENTUREYRA, V.; PALLIER, C., YOO, H. The loss of first language phonetic perception in adopted Koreans. Journal of Psycholinguistics, n.17, p. 79-91, 2004.

WERKER; J. F.; BYERS-HEINLEIN, K. Bilingualism in infancy: First steps in perception and comprehension. Trends in Cognitive Sciences, v.12, n.4, p.144-151, 2008.

YILMAZ, G; SCHMID, M. Second Language Development in a Migrant Context: Turkish community in the Netherlands. International Journal of the Sociology of Language, n.236, p. 101132, 2015.

ZIMMER, M.C. ; ALVES, U. O impacto do bi/multilinguismo sobre o potencial criativo em sala de aula - uma abordagem via Teoria dos Sistemas Dinâmicos. Revista FAEEBA, v. 23, p. 77-90, 2014. 


\section{Abstract \\ Effects of contact between distinct phonetic categories in immigration contexts: a review on first language attrition}

There are still few studies, especially in Brazil, that seek to investigate the process of non-pathological and non-age related first language loss, here taken as language attrition, a frequent phenomenon in the production and perception of speech sounds by immigrants. The aim of this qualitative and bibliographical work is then to present an overview on language attrition and on the effects of contact between distinct phonetic categories in the Voice Onset Time production by immigrants in a dominant L2 context, also seeking to discuss the dynamic character to language, and to popularize this area of investigation.

Keywords: Immigration. Language Attrition. VOT. 